\title{
Extraction of uranium from seawater: a few facts
}

\author{
Joel Guidez and Sophie Gabriel* \\ French Alternative Energies and Atomic Energy Commission, CEA/DEN, Université Paris Saclay, 91191 Gif-sur-Yvette, France
}

Received: 25 September 2015 / Accepted: 19 January 2016

Published online: 4 March 2016

\begin{abstract}
Although uranium concentration in seawater is only about 3 micrograms per liter, the quantity of uranium dissolved in the world's oceans is estimated to amount to 4.5 billion tonnes of uranium metal (tU). In contrast, the current conventional terrestrial resource is estimated to amount to about 17 million tU. However, for a number of reasons the extraction of significant amounts of uranium from seawater remains today more a dream than a reality. Firstly, pumping the seawater to extract this uranium would need more energy than what could be produced with the recuperated uranium. Then if trying to use existing industrial flow rates, as for example on a nuclear power plant, it appears that the annual possible quantity remains very low. In fact huge quantities of water must be treated. To produce the annual world uranium consumption (around 65,000 tU), it would need at least to extract all uranium of $2 \times 10^{13}$ tonnes of seawater, the volume equivalent of the entire North Sea. In fact only the great ocean currents are providing without pumping these huge quantities, and the idea is to try to extract even very partially this uranium. For example Japan, which used before the Fukushima accident about $8,000 \mathrm{tU}$ by year, sees about 5.2 million tU passing every year, in the ocean current Kuro Shio in which it lies. A lot of research works have been published on the studies of adsorbents immersed in these currents. Then, after submersion, these adsorbents are chemically treated to recuperate the uranium. Final quantities remain very low in comparison of the complex and costly operations to be done in sea. One kilogram of adsorbent, after one month of submersion, yields about $2 \mathrm{~g}$ of uranium and the adsorbent can only be used six times due to decreasing efficiency. The industrial extrapolation exercise made for the extraction of 1,200 tU/year give with these values a very costly installation installed on more than $1000 \mathrm{~km}^{2}$ of sea with a lot of boats for transportation and maintenance. The ecological management of this huge installation would present significant challenges. This research will continue to try to increase the efficiency of these adsorbents, but it is clear that it would be very risky today, to have a long-term industrial strategy based on significant production of uranium from seawater with an affordable cost.
\end{abstract}

\section{Very large amounts of uranium}

The average value of the uranium content dissolved in the oceans is estimated at 3.3 micrograms per liter (with dispersal from 1 to 5 micrograms depending on the locations). With a volume in the oceans about $1.37 \times 10^{18} \mathrm{~m}^{3}$, uranium content is estimated to amount to 4.5 billion tonnes of uranium metal $(\mathrm{tU})$ compared to conventional terrestrial resource estimates of about 17 million tU [1-4].

In this connection, Japan, which consumed before the Fukushima accident about 8,000 tU per year, sees about 5.2 million $\mathrm{tU}$ pass by every year in the great ocean current Kuro Schio in which it lies (Fig. 1) [3]. Japan depends entirely on uranium imports, that explains its interest and

\footnotetext{
* e-mail: sophie.gabriel@cea.fr
}

past research effort for extraction of uranium from seawater.

This uranium mainly comes from the soil leaching and related supply from rivers. For example, it is estimated that the Rhone brings $29 \mathrm{tU} /$ year into the sea, and all rivers combined contribute $8,500 \mathrm{tU} /$ year.

These virtually inexhaustible quantities have, sporadically since the $1950 \mathrm{~s}$, led to much research on the possibility of extraction. The recently launched American Department of Energy program is to develop a realistic cost of production to inform future fuel cycle decisions, i.e. whether to reprocess or not.

Note: All metal ions are also found dissolved in seawater in significant overall amounts and often greater than known mineral resources. Only three products: $\mathrm{NaCl}, \mathrm{MgCl}_{2}$ and $\mathrm{MgSO}_{4}$ can be easily extracted, for example by evaporation. The values for the others are much too low and require more complex selective strategies. It should also be noted that some interesting 


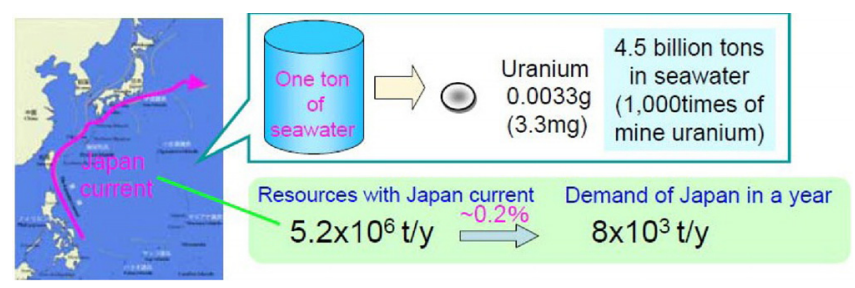

Fig. 1. Amounts of uranium present in the oceans and ocean current near Japan [3].

products such as lithium or indium may also be involved in this research on extraction techniques.

\section{Energy balance of extraction}

\subsection{Extraction by pumping}

A tonne of seawater therefore contains about 3.3 milligrams of uranium. Every year France uses 8,000 t of natural uranium to produce about $420 \mathrm{TWh}$, i.e. $52.5 \mathrm{kWh}$ per gram of uranium. The complete extraction of the uranium contained in a cubic meter of seawater (which is not the case), would let to produce about $0.17 \mathrm{kWh}$ of electrical energy in current nuclear water reactors.

The electrical energy required to raise $1 \mathrm{~m}^{3}$ by $10 \mathrm{~m}$ is about $0.03 \mathrm{kWh}$ (with a yield of $80 \%$ ). In addition, there is a pressure drop in the pipes and the filtration membrane. In seawater desalination plants, for example, energy consumption is estimated around $2.5 \mathrm{kWh}$ per tonne [2], well above the $0.17 \mathrm{kWh}$ that could be recovered. Thus, by applying the simple rule of three to the energy balance, the infeasibility of a land-bound plant dedicated to extracting uranium from seawater can be seen.

\subsection{Existing pumping facilities unusable}

There are significant seawater pumping facilities in nuclear power plants, seawater desalination facilities or tidal power plants. But the amount of uranium that could be hoped from them remains low and therefore unrealistic in relation to the difficulties: increased head losses, actual efficiency, problem of waste and local depletion in terms of concentration, etc.

A 1,000 MWe nuclear reactor, for example, will use an annual seawater flow of about 40 million cubic meters. This represents the flow of only $130 \mathrm{~kg}$ of uranium. Even if all of it could be recovered (which is impossible), this would, at the current market price, represent a budget of 12,000 euros which of course would not even cover installation and operating costs. Incidentally, this amount is less than one thousandth of the annual consumption of the same reactor (150 tU).

The same reasoning applies to seawater desalination units, where the maximum extractable quantities, and therefore the available budget, remain very low in relation to the operations to be performed.

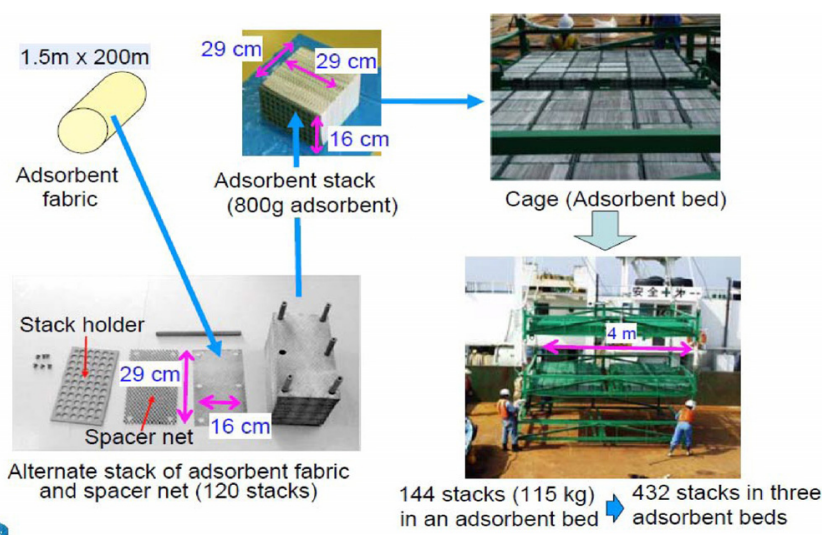

Fig. 2. Construction of a platform in which each stack has $115 \mathrm{~kg}$ of adsorbent [3].

\subsection{Use of ocean currents}

The amounts of water to be treated are huge compared to the objectives. This is the basic problem.

To produce the total amount of uranium currently consumed worldwide every year (about 65,000 tU) and assuming an infeasible $100 \%$ yield, $2 \times 10^{13}$ tonnes of water would have to be processed annually, in other words: the entire North Sea [2]. Only the great ocean currents are able to supply these volumes: the Gulf Stream, Kuro Shio in Japan, Strait of Gibraltar, etc.

The idea is thus to treat these major currents which would also solve the problem of depletion and renewal of seawater, for a land-bound plant. The concept of pumping, filter and efficiency no longer applies. It would be an extraction in the water.

\section{Update on extraction techniques}

Attention has therefore turned to using adsorbents that can collect the uranium (along with other components) in a selective way. Then these adsorbents are removed and the deposits recovered, generally by a chemical process.

In the 1960s, titanium oxide hydrate was used $[5,6]$, but the latest publications refer to the use of amidoxime [5-9], which has a significantly higher yield.

In-laboratory point values of $2 \mathrm{~g} / \mathrm{kg}$ of adsorbent per month, or more, have thus been announced (the most recent laboratory batch experiments of the Oak Ridge National Laboratory [ORNL], in 2013, have shown the higher performance: $3.3 \mathrm{~g} / \mathrm{kg}$ of adsorbent after 8 weeks of contact of the adsorbent with seawater [8]).

The performances are much lower in more realistic conditions. In 2009, JAEA presented result from marine experiments [3,6]. The device was three superimposed platforms, containing $115 \mathrm{~kg}$ of absorbent on supports (Figs. 2 and 3).

Table 1 shows the extraction cycles for this system from 1999 to 2001 and the amount of uranium recovered, i.e. $1,083 \mathrm{~g}$ over the 12 cycles of 20 to 96 days of immersion. 
Table 1. Assessment of offshore extraction cycles [6].

\begin{tabular}{llllrr}
\hline \multicolumn{2}{c}{ Submersion period } & Submersion days & $\begin{array}{l}\text { Seawater temperature } \\
\left({ }^{\circ} \mathrm{C}\right)\end{array}$ & Number of stacks & $\begin{array}{c}\text { Adsorbed uranium } \\
(\mathrm{g})[9]\end{array}$ \\
\hline 1999 & 29 Sep.-20 Oct. & 21 & $19-21$ & 144 & 66 \\
2000 & 8 Jun.-28 Jun. & 20 & $12-13$ & 144 & 47 \\
& 28 Jun.-8 Aug. & 40 & $13-22$ & 144 & 66 \\
& 8 Aug.-7 Sep. & 29 & $20-24$ & 144 & 101 \\
& 7 Sep.-28 Sep. & 21 & $24-22$ & 144 & 76 \\
2001 & 28 Sep.-19 Oct. & 21 & $20-18$ & 144 & 95 \\
& 15 Jun.-17 Jul. & 32 & $13-18$ & 216 & 119 \\
& 18 Jul.-20 Aug. & 32 & $18-20$ & 216 & 48 \\
& 15 Jun.-20 Aug. & 65 & $13-20$ & 216 & 118 \\
& 20 Aug.-21 Sep. & 31 & $20-19$ & 144 & 150 \\
& 18 Jul.-21 Sep. & 63 & $18-19$ & 72 & 120 \\
\hline
\end{tabular}

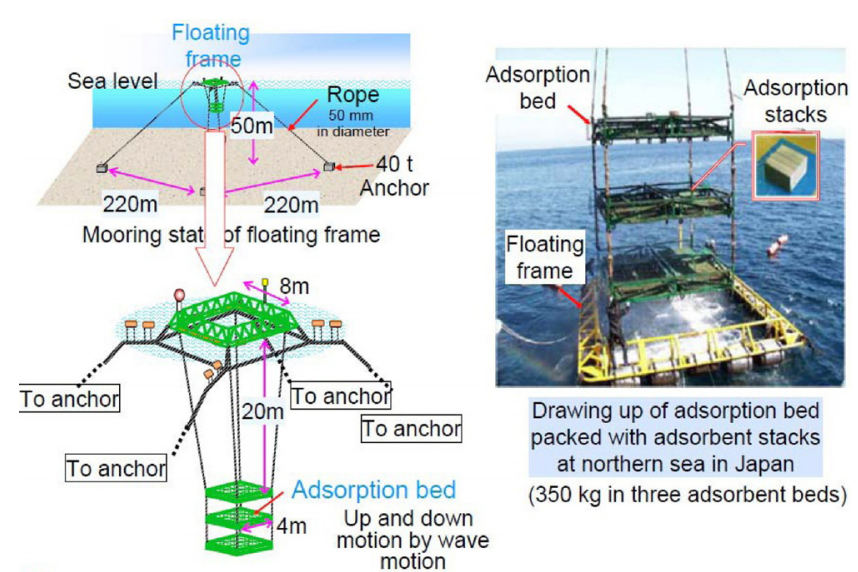

Fig. 3. Complete offshore platform with the three stacks shown in Figure 2 [3].

The values clearly fluctuate, but the average value is less than $1 \mathrm{~g}$ of uranium per kilogram of absorbent and per month: lower than the "ideal" laboratory values. Even if the more recent batch laboratory experiments with the new adsorbent of ORNL are better (2.6 times higher than that of the JAEA adsorbent under similar conditions [8]), it is still very low.

These methods are confronted with many problems in the field:

- drop in performance after each chemical wash/limited number of cycles;

- influence of various parameters on the performance such as water temperature, wave height, etc.;

- deposits of algae and shells;

- problems related to installing offshore operations (access, weather conditions, resistance to corrosion of structures, etc.);
- significant amounts of adsorbent to be used, processed and renewed.

The important role played by temperature, which is to be as high as possible $\left(25^{\circ} \mathrm{C}\right.$ or more $)$ is also obvious. The cycles were carried out from June to October.

\section{Cost analysis}

Researchers working in field announced until the 1980s targeted a price range between 1,000 and 2,000 USD $/ \mathrm{kgU}$. After, using point results of better efficiency in terms of grams per kilogram obtained in the laboratory, prices were reduced accordingly and announced between 300 to $600 \mathrm{USD} / \mathrm{kgU}$. More recent cost analyses have been made by the Japanese and also by the American Department of Energy $[7,10]$. The prices quoted are then between 1,000 and $1,400 \mathrm{USD} / \mathrm{kgU}$.

The lowest values can be perplexing when you consider the example from the previous section and all the qualified personnel and work required to recover a kilo of uranium in one year: construction of the platform, offshore operations for installation and periodic extraction, onshore processing of the adsorbent, periodic replacement of 115 kilos of adsorbent, etc. What is the final cost of this kilo of uranium?

In fact, these costs announced were derived from extrapolations for gigantic installations. The systems are immersed over several kilometers (see Fig. 4 for a project with an annual output of $1,200 \mathrm{tU}$ ) as well as shuttle boats and on-shore treatment plant. This should lead to industrial rationalization and a related reduction in costs. It is clear that all costs associated with developing and operating these huge facilities have not yet been determined, particularly for the installation, anchoring, and location of these thousands of offshore platforms, and those costs announced are little more than rough, first order estimates. 


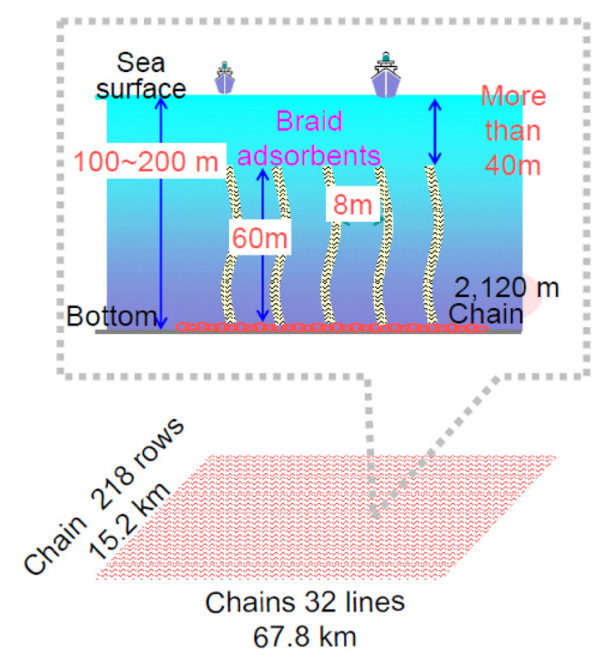

Fig. 4. Offshore extraction plant project [3].

For the more recent cost analyses $[7,10]$ (prices between 1,000 and $1,400 \mathrm{USD} / \mathrm{kgU}$ ), the initial parameters used are as follows (for a plant that would produce 1,200 tU/year):

- capacity of the adsorbent at $2 \mathrm{~g} / \mathrm{kg}$;

- 60 days of immersion;

- temperature of the water at $25^{\circ} \mathrm{C}$;

$-5 \%$ drop in efficiency of the adsorbent after each chemical rinse;

- using the adsorbent six times (after which it has to be replaced).

It appears that the primary key parameter of the cost model is the adsorbent's capacity in $\mathrm{g} / \mathrm{kg}$. The mathematical model is thus used to significantly reduce costs when going from $2 \mathrm{~g} / \mathrm{kg}$ to 4 and then 6 (the last test presented in $2013[8,10]$ had reached $3.3 \mathrm{~g} / \mathrm{kg}$ in 8 weeks of immersion, 2.6 higher than the previous).

All this remains theoretical. The anchoring of these systems over several miles at sea has yet to be defined. What is the drop in efficiency in winter? Is there a depletion over the kilometers of adsorption which would also adversely affect efficiency? What about corrosion and structural maintenance? None of these issues are addressed in the presentation of the model.

\section{Difficulties}

\subsection{Environmental problems}

It should also be noted that the environmental impact of a facility covering over $1,000 \mathrm{~km}^{2}$ would certainly be prohibitive. Similarly, the amount of chemical by-products produced and handled would be extremely large and also lead to environmental problems.

\subsection{Energy balance}

Many massive facilities have to be constructed and submerged, tonnes of adsorbent have to be made and renewed, and conventional island component cooling system boats have to go back and forth. The document [2] addresses this point in an original way. Using statistics for fishing costs and related fuel consumption, an estimated $5 \mathrm{kWh} / \mathrm{kg}$ is required to extract something free from the sea and bring it back to shore. However, to produce $1 \mathrm{~kg}$ of uranium approximately $500 \mathrm{~kg}$ of adsorbent have to be handled, i.e. 2.5 MWh per kilogram of uranium produced, for one-way transportation only (a free return trip is assumed, as the boat would not travel unloaded). Similarly, the production of these adsorbents with a limited lifespan also requires energy, estimated in reference [2] at $10 \mathrm{MWh}$ to produce $500 \mathrm{~kg}$ of adsorbent (assuming a one-year life cycle, which is optimistic). These calculations, which are already very rough, mean that $12.5 \mathrm{MWh}$ would be used to produce a kilogram of uranium which in turn can theoretically generate about $52.5 \mathrm{MWh}$ in a reactor. And all other energies required in the process should be added to achieve an accurate balance.

This energy balance work was carried out in much greater detail by the project proponent [11], which uses more optimistic and lower values than those above. It reaches an EROI (Energy Return On Investment) of 12, a value which is clearly subject to a number of parameters. It should be noted that the EROI is more than 300 times higher for mined uranium.

\subsection{Strategy for the nuclear industry}

Without a demonstration of industrial feasibility and validation of a credible cost of extraction, it would be extremely risky to work on a long-term industrial strategy based on significant production of uranium from seawater at an affordable cost.

It is worth remembering that fast reactors could be operated without the need for new resources of natural uranium for millennia. The economic profitability would be ensured well before the market price of uranium reaches the estimated cost of uranium production from seawater.

\section{Conclusion}

There is an extremely large quantity of uranium solute in the oceans but its low concentration would require a volume of water greater than that of the North Sea to be processed every year in order to extract uranium currently consumed worldwide every year.

Basic energy balances show that pumping/filtering systems have no interest and no future.

The only other solution would be extraction by adsorbents placed in ocean currents naturally and freely providing drive and renewal of very large flowrates. These techniques currently enable the production of small quantities at prohibitive prices. Extrapolation on an industrial scale has yet to be developed, even in terms of feasibility, and the final cost of production has not yet been firmly established. 
However, the continuation of this research is interesting if the efficiency of the process can be further improved, and applied to other materials of interest, so as to pool prohibitively high costs of production.

It would however, given current knowledge, be extremely risky for the nuclear industry to launch an industrial strategy based on the possible extraction of uranium from seawater, in an affordable way.

\section{References}

1. B. Barre, G. Capus, L'uranium de l'eau de mer : véritable ressource énergétique ou mythe ? [Uranium from seawater: real energy resource or myth?], Revue des ingénieurs (Engineers review), 2003

2. U. Bardi, Extracting minerals from seawater: an energy analysis, Sustainability 2, 980 (2010)

3. M. Tamada (JAEA), Collection of uranium from seawater, Presentation of 5/11/2009 in Vienna (IAEA)
4. OECD/NEA IAEA, Uranium 2014: Resources, Production and demand, 2014

5. P. Blanchard, S. Gabriel (CEA), Extraction d'uranium de l'eau de mer (Uranium extraction of seawater), Letter from Itésé Number 11, 2010

6. M. Tamada (JAEA), Current status of technology for collection of uranium from seawater, ERICE seminar, 2009

7. E. Schneider et al., Cost and system analysis of recovery of uranium from seawater, DOE paper presented the 31 October 2012 (Chicago / ANL)

8. C. Tsouris et al., Uptake of uranium from seawater by amidoxime-based polymeric adsorbent: marine testing, in Global 2013 (2013), paper 8438

9. L.K. Felker et al., Adsorbent materials development and testing, for the extraction of uranium from seawater, in Global 2013 (2013), paper 8355

10. E. Schneider, D. Sachde, The cost of recovering uranium from seawater by a braided polymer adsorbent system, Sci. Global Secur. 21, 134 (2013)

11. E. Schneider, H. Lindner, Energy balance for uranium recovery from seawater, in Global 2013 (2013), paper 7427

Cite this article as: Joel Guidez, Sophie Gabriel, Extraction of uranium from seawater: a few facts, EPJ Nuclear Sci. Technol. 2, 10 $(2016)$ 